\title{
Group Dynamics and Peer-Tutoring a Pedagogical Tool for Learning in Higher Education
}

\author{
Muhammad Azeem Qureshi \\ Associate Professor \\ School of Business \\ Oslo and Akershus University College of Applied Sciences, Oslo, Norway \\ E-mail: muhammad-azeem.qureshi@hioa.no
}

Even Stormyhr

Senior Lecturer

Department of Film and TV, School of Communication, WSoC University College of Communication, Oslo, Norway

E-mail: even@westerdals.no

Received: October 19, 2011 Accepted: November 3, 2011 Published: April 1, 2012

doi:10.5539/ies.v5n2p118

URL: http://dx.doi.org/10.5539/ies.v5n2p118

\begin{abstract}
The increasing diversity in students' enrolment in higher education in Norway offers an opportunity to use collaborative learning and teamwork as a learning vehicle to exploit the synergy in the community to have formal and informal agoras. Theoretical and empirical observation of the value of team processes provides the framework to personify our understanding of learning and present a model for teaching in higher education in Norway. We consider learning as a holistic process and one must appreciate its dynamics and be flexible and responsive to it. Moreover, such a view of the entire process necessitates an active communication with all stakeholders of the system and to make an integrative and coordinated effort to ensure availability of the required institutional resources, equitable distribution of the students' resources, and a smooth transition from the traditional lecturing to this form of collaborative learning to make higher educational institution a learning organization. We report a positive feedback from the students attending two courses at School of Business at HiOA, indicating that students consider this teaching method adding more value compared to traditional lecturing.
\end{abstract}

Keywords: Group dynamics, Peer-tutoring, Higher education, Collaborative learning, Inclusive learning environment, Social interaction

\section{Introduction}

Over the last two decades we observe a proliferation of development of alternative teaching methods and their integration with traditional programs (Colvin, 2007). Collaborative learning is one such method applied in different settings and during the last decade researchers have been analyzing learning as a social practice. The socio-cultural perspective considers the learning as a collaborative process and research demonstrates that students working in small groups develop not only a deeper understanding of the subject matter but also develop some of the key professional competencies such as critical thinking, communication skills, interpersonal relations, and self-assessment (Chaves, Baker, Chaves, \& Fisher, 2006). Contrary to the orthodox conduit of 'teacher is the only authority', collaborative learning bases itself on accepting and granting authority among students (Fougner, Tønnesson, \& Utne, 2008; Michaelsen, Knight, \& Fink, 2004). This construct weaves teacher, tutor and tutee into a learning community (Fougner, 2011), where dynamics of social interaction help facilitate an inclusive learning environment because we consider teaching and learning as highly social activities from a social-cognitive theoretical perspective (Bandura, 1986; Vygotsky, Cole, John-Steiner, Scribner, \& Souberman, 1978). We use these theories and theories of group dynamics to ground our teaching model which we propose to be used in Norwegian higher education system.

The students' enrolment in higher education in Norway is becoming increasingly diverse in terms of ethno-cultural, 
socio-economic and even linguistic backgrounds. Considering varying level of interest and preparedness of the students adds further complexity to the observed diversity among students and makes the job of teaching community in higher education in Norway further challenging. We observe that such a diversity offers an opportunity to use collaborative learning and teamwork as a learning vehicle because research demonstrates that such methods not only help learning in diverse and challenging environment but may also facilitate harmony in society (Underhill \& McDonald, 2010). Moreover, collaborative learning confers upon teachers three types of responsibilities: teaching, supervision, and learning facilitation. While the traditional teaching method draws away the teacher from supervision and learning facilitation to make teaching as the main responsibility. We consider the need for sharpening the supervisory and mentoring skills of teachers as a developmental opportunity to practice collaborative learning and teamwork as a teaching method.

Banking on the above identified opportunities in Norwegian higher education system, theoretical and empirical evidence found in literature, having inspiration from an earlier work in Norwegian context ${ }^{1}$ and learning from our own experiences from two different and diversified perspectives and disciplines ${ }^{2}$ we present a model that bestows upon students the responsibility of their own learning by unlocking their learning potential through teamwork and social interaction to promote critical thinking, communication, and collaboration to inculcate in them a desire and an ability to influence the development of society from their choice of occupation; and gives teachers an opportunity to continuously improve their multidimensional skills to better discharge their responsibilities. Based on our theoretical grounding, we consider social interaction as a key mechanism in the process of teaching, and learning and development wherein the interactions with teacher, teaching materials and among peers influence the cognitive development of learners (Vygotsky, et al., 1978).

The core intent of our model is to integrate knowledge with socio-cultural characteristics of group dynamics to create an ambient of lifelong learning. We expect that an organization wide holistic and integrated approach and its persistent practice will transform the educational institution into a learning organization to make it an inclusive institution that promotes learning via sustainable collaboration and equality (Topping \& Maloney, 2005).

We organize rest of the paper as follows. Section 2 reviews some of the relevant literature, Section 3 describes the model. Section 4 presents and discusses the survey results and Section 5 puts forward the conclusions drawn and provides policy recommendations. We present the references at the end.

\section{Framework}

We use social-cognitive, socio-cultural and group dynamics theories to weave our teaching construct around the dynamics of team which bestows responsibility and opportunity to the individuals to be part of a community in which they can communicate and influence others. A typical classroom lecture engenders a grade-centered students' milieu (Panitz \& Panitz, 1998), wherein the orthodox conduit of 'teacher is the only authority' promotes teacher-student hierarchical structure that may limit the inquisition among students and prove to be a barrier to effective learning (Bonwell \& Eison, 1991). However, the students-centered alternative approaches reduce typical hierarchical structure (Lopez, 1999), promote critical thinking, communication, and collaboration considered as key elements of lifelong learning (Falchikov, 2001; Smith \& MacGregor, 1992). Generally, peer tutoring uses senior students as tutors of their junior peer tutees. But we take a different position. To further eliminate any hierarchy that might be associated with common practice of peer tutoring, our model requires the same student to be a tutor as well as tutee via role swapping. The intent of our model is to minimize typical hierarchical structure; teacher-student as well as tutor-tutee; to minimize the barriers to effective communication (Bonwell \& Eison, 1991), to unlock their learning potential through functional group processes via different group constellations and through inspiring challenges (Sletten \& Stormyhr, 1993). We envision that such a process will provide opportunities to communicate not compromising the need of others to express themselves, but on the contrary, encourages increased communication and enhanced dialogue. This type of communication facilitates not only quality assurance but also promotes development as well as harmony in increasingly diverse milieu.

Our teaching model uses teams as engine of learning where students learn from each other's skills and thus indirectly teach each other. Teamwork also helps to highlight the different qualities of the role and the interaction between roles thus preparing the students to take on the challenges facing them in real life. This is a crucial starting point for students when they themselves will later lead a team, or they will join a team where one is expected to "play each other good". We argue that there exist two level dynamics: first, explicit level that deals with practical exercises using roles performed by each team member; and second, implicit and a more process-oriented unspoken level that is about interaction and human phenomena among team members. No group starts out as a team. But a holistic approach of making the group more inclusive, role swapping, open and clear communication channels, and behavior conditioning through effective feedback is likely to convert the work groups systematically into effective 
development teams. Synergy of the two processes will help effective achievement of the defined objectives. But it may also have negative impact on students' anticipated learning if not handled properly. A study in USA carried over 18-month period indicates that peer tutors and students may spend excessive time in impression management, and misunderstanding and power struggle may prevail (Colvin, 2007).

\section{The Model}

Our model bases itself on imparting knowledge by providing tasks, in the form of relevant and meaningful challenges linked to the key learning outcomes, to the students put into a team context in which students serve as each other's development partners. We consider our model as a holistic and integrative learning process comprising of five phases: Plenary, Teamwork, Meta-reflection Teams, Teamwork-II and Feedback in Plenary. It is imperative to note that this teaching method is radically different from what is generally in practice in Norwegian higher education system. Therefore, we strongly advocate an active communication with all stakeholders of the system so that its essence is understood and absorbed before an organization wide practice because research demonstrates that the students understand and experience the benefits of learning in small groups if such an initiative is well coordinated at institutional level (Hillyard, Gillespie, \& Littig, 2010).

To make this method effective we emphasize the need to invest a reasonable time to structure the course contents and the challenges/tasks which are related to the key learning outcomes of each session and have practical orientation based on a case or a scenario. The challenges/tasks and deliverables along with the reading material are published well in advance. This is likely to yield three benefits: first, it will necessitate communication among team members; second, it will make them to read in advance and increase the level of preparedness of the students; and third, each one can come up with a responsibility to solve the task within a limited time to make them effective team members to help avoid free rider tendency. This independent work will facilitate making the team functional as each team member has something to contribute to the teamwork. We emphasize that a clear communication of the process, the structure and the deliverables is the key to make students confident of their own potential for change so that they are able to challenge themselves and the current practices.

\subsection{Phase-I: Plenary}

The purpose of Phase-I, called Plenary, is to provide the key learning outcomes, theoretical background, and key concepts in the form of a briefing. The teacher then hands out the challenges and the tasks to be carried out by the students in teams in Phase-II. Teacher's role here is to illuminate the task and to create enthusiasm. The students are challenged to be involved to understand, to take a stand for what they communicate/produce, to make constructive critical questions, and in the process be involved to further develop their field. Thick arrows emanating from centre, the teacher in the middle in Figure 1, portray a generally unidirectional communication flow where teacher introduces the theory; clarifies the concepts; provides information and inputs; assigns task and sets goals and targets. Nevertheless students may also seek clarification if needed which we portray as dashed arrows. This phase is more like a traditional lecture but we accentuate on two-way communication flow. The students are expected to be active participants by way of advance reading and active dialogue with the teacher.

Insert Figure 1: Phase-I: Plenary here.

\subsection{Phase-II: Teamwork}

After the Plenary and a break, the students will assemble for the Teamwork. The objective of this phase is to unlock the students' learning potential through group dynamics and social interaction where peer tutoring is the learning mechanism and effective teamwork is the engine of learning and development. Depending upon the class size, the class will be divided in 3-5 (almost) equal sized teams (Figure 2). While doing so the team should be such that it facilitates effective team dynamics, avoids free-rider tendency and represents the equitable distribution of students' resources. The teams are required to practically apply the theoretical frameworks provided in the Phase-I to achieve the set targets. Ideally each team will get a different task/case/scenario to apply the concepts learnt in Phase-I. We expect equitable distribution of students' resources and managing effective team dynamics as key challenges of Phase-II. Teacher's role in this phase is to be a supervisor and a process facilitator in relation to both team process and problem-solving to make team more inclusive where an active debate is promoted to bring out who knows what; what is not clear; and what is missing; etc. They take the responsibility of transferring knowledge and skills from those who possess such to those who do not.

Insert Figure 2: Phase-II: Teamwork here

\subsection{Phase-III: Meta-reflection Teams}

After completion of their tasks in Teamwork and enjoying a short break, the students are re-grouped in Phase-III by drawing members from each team to make Meta-reflection Teams (mind the color in Figure 3) the number of which 
should be equal to the number of teams. The purpose of this phase is knowledge dissemination by engaging students in meta-reflection to effectively communicate (tell and be told) their learning in Teamwork. In this way all the students share their experiences and also get insights into the work of others. Such a two way communication is expected to help them train not only for the course requirements but also for their future professional career. The teacher assumes the role of process facilitator to unlock the communication barriers, if any, to facilitate broad-based, deep and cross-functional learning.

Insert Figure 3: Phase-III: Meta-reflection Teams here

\subsection{Phase-IV: Teamwork-II}

The purpose of this phase is to bring home the cross-functional knowledge from Meta-reflection Teams to further improve the learning and deliverables of the teams. The structure of this phase is similar to Phase-II. The students share the learning obtained from the Meta-reflection Teams to improve their learning and knowledge as well as to improve the deliverables of the task. At the end of this phase the teams will hand-in their response to the assigned task. A revisit of the content and the process will help inculcate deep learning among the students and will condition their behavior to be critical thinkers.

\subsection{Phase-V: Feedback in Plenary}

After Teamwork-II and enjoying a break, the students meet again in Feedback in Plenary session which is Phase-V of this model, which we present in Figure 4. The purpose of this phase is to provide feedback to the students of the evaluation made by the teacher of process as well as content related parameters. During the process the teacher has acquired a good understanding of the level of students' functional understanding of the course contents as well as their process related abilities, for example their communication and collaboration skills. A candid assessment/feedback about these parameters would make the group processes effective and smoother for the next sessions to facilitate deep and inclusive learning. The teacher will also provide prototype response to the deliverables of the tasks and in the end the teacher will also provide the summary of the day's contents.

Insert Figure 4: Phase-V: Feedback in Plenary here

We argue that by being confronted with other people's viewpoints, ways of working and life philosophies, the students are challenged to develop their own attitudes and broaden their own perspective. Creative friction, that brings development and innovation, will arise where differences are not seen as threat but a way forward. This demands an institution wide integrative and holistic approach to provide a learning environment that can accommodate differences, and a learning context where students are each other's development partners.

\section{Survey}

We come from two different cultural and professional backgrounds having diversified professional careers but share a common experience; acquired over the years from our own education and training as well as professional career; that teamwork helps improve learning in diverse educational and professional environments. Building on this common ground and relevant pedagogical literature we put forward a teaching model by incorporating our vision of considering learning as a 'holistic process'. Based on our experience of practicing a short version of this model, we argue that our model is flexible and dynamic in nature which is portable to different situations may it be education or professional training, and thus robust. However, to seek opinion of our learned colleagues at our institutes; Høgskolen i Oslo og Akershus and Westerdals School of Communication; we presented our model to them. We report reflections of our peers in the following paragraphs.

\subsection{Høgskolen i Oslo og Akershus}

The model was presented to the colleagues (10) at School of Business at Faculty of Social Sciences. With the invitation a background paper describing the model was also sent. After a 15 minutes' presentation, there was a questions answer session of around half an hour. Contextualizing the model in business education, we described the model implementation in a 180 minutes session (Table 1). Nevertheless, we are not rigid in our approach but consider this time plan as flexible and dynamic wherein the teacher may amend the duration of entire process as well as individual phases as per specific needs.

Insert Table 1: Time plan for one session here

The model was well received and a number of questions/observations were made. At the end of the session, a questionnaire was given to them to solicit their opinion about the model. We received 5 duly filled-in responses. The following paragraph presents their written as well as verbal reflections.

They considered this method very good and interesting. They observed that problem based learning is generally considered effective but use of Meta-reflection Teams is innovative to promote critical thinking among students that 
will facilitate lifelong learning. Some of the colleagues were of the view that five phases is too much to handle in 180 minutes, and also that such a structure may create problems related to logistics. Some suggested changes in time for some Phases to which they were told that this is quite flexible and up to the teacher to decide. Another view point was that such a method may not be suitable for large classes (over 100 students), and for the subjects like mathematics and statistics. Moreover, for an effective outcome one must appreciate the following as major challenges:

- Course development and design especially developing the tasks/challenges.

- Managing team dynamics to make them more inclusive as well as effective.

- Supervision and continuous evaluation.

- Ability to remain flexible and responsive to the situational dynamics.

Further, we report very encouraging feedback from the students to the course instructor (first author) and to the Head of School of Business at HiOA. We continuously incorporate their inputs and situational factors to improve the logistics and other operational details but basically sticking to the overall framework.

\subsection{Westerdals School of Communication}

We presented our model to the colleagues (4); who represent the school's two institutes, Institutt for Fortellingsmedier and Institutt for Kommunikasjonsdesign and the administration represented by a project manager responsible for organizing fellesfag. With the invitation a background paper describing the model was also sent. We gave a 15 minutes' presentation followed by a questions answer session of around 45 minutes. We described the model implementation in to the school's first semester foundation projects where all first year students are involved on a multidisciplinary basis.

The enthusiasm and the questions reflected appreciation of the colleagues. At the end of the session we gave them a questionnaire to seek their opinion about the model. We describe their view point in the following paragraph.

The response was that the proposed model seemed to be both relevant and useful, particularly for the interdisciplinary subjects with larger student groups. They also observed the model to be relevant in their context that would make the students to reformulate their learning into their own words and in this way integrate knowledge. The learning process formulated by way of social interaction may trigger students' discovery of their own needs for solving the task at hand. The use of Meta-reflection Teams makes everyone responsible for their own learning. One of the colleagues was very much interested in implementing this method in her teaching but over a span of a couple of days, or a week but to get hands on experience she would like to observe a session of a colleague having some experience in this kind of teaching bringing peer tutoring into the teacher's learning.

\section{Conclusion}

We observe a need, in higher education in Norway, to unlock the students' potential to learn by using teamwork to exploit the synergy in the community and create good exchanges between groups and individuals in a way that gives relevance in a society for development. We consider it imperative to have formal and informal agoras or meeting places where theory, craft, and society is discussed and debated. Theoretical and empirical observation of the value of team processes provides the framework to personify our understanding of learning.

We argue that for a deeper and critical learning, the students must experience the lectures/tasks/challenges that the teacher provides as relevant, interesting and manageable. For this purpose, we stress upon the teachers the need to invest sufficient time to structure the course contents, specify the key learning outcomes, develop challenges and tasks linked to key learning outcomes, identify the assessment parameters, and above all consider this learning process holistic in nature and appreciate its dynamics and be flexible and responsive to it. Moreover, we emphasize to dramatize the challenge/task to provoke a reaction to raise curiosity and ambitions to solve the tasks that lie within the challenge.

We consider the role swapping, for both the teacher and the students, as a key mechanism to sustain enthusiasm during the learning process. We stress that the teacher as well as students have to be actively aware of and responsive to the needs of each role. Moreover, the teacher must actively facilitate smooth and effective team functioning through management of group processes.

We use evaluation and feedback as a behavior conditioning tool to give students an insight into how they can duplicate the success and reorganize themselves and their work in a more appropriate manner to face the next task/challenge. By frequent integration of the knowledge, practical skills, and the evaluation and feedback provided the students an analytical and methodical understanding that leads to professionalism to replicate success in their career. 
We consider optimum utility of this method may be achieved with a medium-sized class not exceeding 70 students. However, if the class size increases then we recommend that either two or more teachers should collaborate or the teacher may hire some teaching assistant(s) as a help for Phase-II and III. A holistic view of the entire process necessitates an active communication with all stakeholders of the system and to make an integrative and coordinated effort to ensure availability of the required institutional resources, equitable distribution of the students' resources, and a smooth transition from the traditional lecturing to this form of collaborative learning to make higher educational institution a learning organization.

\section{Acknowledgement}

This paper was developed during a semester long training course in spring semester 2011 at Pedagogisk Utvikling Senteret of HiOA. Authors are thankful to Professor Gerd Bjørke for her professional guidance during completion of this paper. We also thank our colleagues at this course as well as HiOA and WSoC for their professional inputs. Moreover, we are thankful to the students at HiOA for their valuable feedback and inputs for continuous improvement in this teaching method.

Per Stormyhr and Tor Sletten of Instituttet for Gruppedynamik were invited to work with the people unemployed since long in Drammen with the objective of getting these people back in work. They developed a concept called the Omstillingsprogram for Langtidsledige. A pilot project was executed for over a 3 months' period from 24.10.94 to 01.02.95. The project is well documented through an end report consisting of the description of the model and 1678 evaluation answers from the 23 participants.

\section{References}

Bandura, A. (1986). Social Foundations of Thought and Action: A Social Cognitive Theory. Englewood Cliffs, NJ: Prentice Hall.

Bonwell, C., \& Eison, J. A. (1991). Active learning: creating excitement in the classroom ASHE-ERIC Higher Education Reports. Washington DC.

Chaves, J. F., Baker, C. M., Chaves, J. A., \& Fisher, M. L. (2006). Self, Peer, and Tutor Assessments of MSN Competencies Using the PBL-Evaluator. Journal of Nursing Education, 45(1), 25-31.

Colvin, J. W. (2007). Peer tutoring and social dynamics in higher education. Mentoring \& Tutoring: Partnership in Learning, 15(2), 165-181. http://dx.doi.org/10.1080/13611260601086345

Falchikov, N. (2001). Learning together: peer tutoring in higher education Florence, KY, USA.

Fougner, A. (2011). Exploring knowledge through peer tutoring in a transitional learningcommunity: An alternative way of teaching counseling skills to students in social work education British Journal of Social Work Education, forthcoming (in press).

Fougner, A., Tønnesson, H., \& Utne, B. (2008). What do students learn from facilitating the learning process of younger students? Nordisk Pedagogik, 28, 287-302.

Hillyard, C., Gillespie, D., \& Littig, P. (2010). University students' attitudes about learning in small groups after frequent participation. Active Learning in Higher Education, 11(1), 9-20. http://dx.doi.org/10.1177/1469787409355867

Lopez, C. L. (1999). A decade of assessing student learning: What we have learned; what's next? Chicago: North Central Association of Colleges and Schools.

Michaelsen, L., Knight, A., \& Fink, D. (Eds.). (2004). Team-based learning: Sterling, VA: Stylus.

Panitz, T., \& Panitz, P. (1998). Ways to encourage collaborative teaching in higher education. In J. J. Forest (Ed.), University teaching: International perspectives (pp. 161-202). New York: Garland Publishing.

Sletten, T., \& Stormyhr, P. (1993). Omstillingsprogram for Langtidsledige: Instituttet for Gruppedynamikk

Smith, B. L., \& MacGregor, J. T. (1992). What is collaborative learning? In A. S. Goodsell, M. R. Maher \& V. Tinto (Eds.), Collaborative learning: A sourcebook for higher education (pp. 9-22): University Park, PA: National Center on Postsecondary Teaching, Learning, and Assessment.

Topping, K., \& Maloney, S. (Eds.). (2005). The RoutledgeFalmer Reader in Inclusive Education. London and New York: RoutledgeFalmer, Taylor \& Francis Group

Underhill, J., \& McDonald, J. (2010). Collaborative Tutor Development: Enabling a Transformative Paradigm in a South African University. Mentoring \& Tutoring: Partnership in Learning, 18(2), 91-106. http://dx.doi.org/10.1080/13611261003678853 
Vygotsky, L. S., Cole, M., John-Steiner, V., Scribner, S., \& Souberman, E. (1978). Mind in society: Cambridge, MA: Harvard University Press.

\section{Authors}

Dr. Qureshi is a Pakistani national and an Associate Professor of Finance at School of Business, HiOA. He has over 21 years of professional and teaching experience. He has also been management trainer with Coca-Cola and other business firms operating in Multan, Pakistan. Mr. Even Stormyhr is a Norwegian national. He is a Senior Lecturer at WSoC and has more than 15 years of professional and teaching experience from the film and TV industry in Norway and Italy. He founded the Film and TV department at WSoC in 2001 working as head of department until 2008. He has developed several didactical/pedagogical programs for different film and communication schools. From 93-95 he was trainee at Instituttet for Gruppedynamikk.

Table 1. Time plan for one session

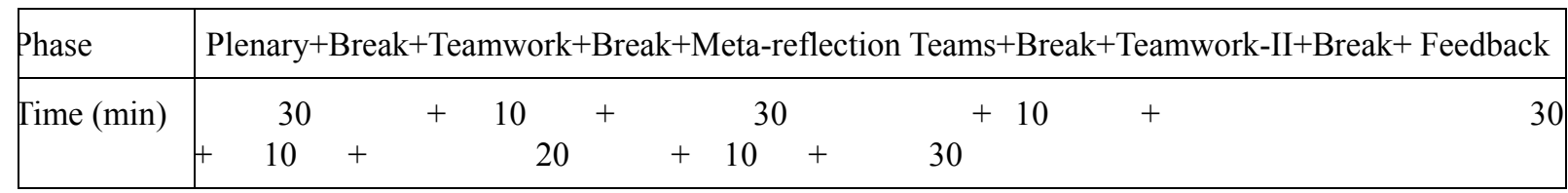

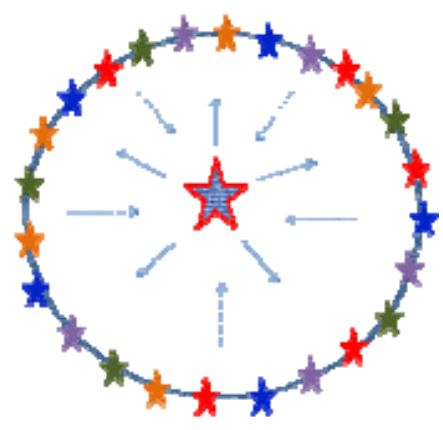

Figure 1. Phase-I: Plenary

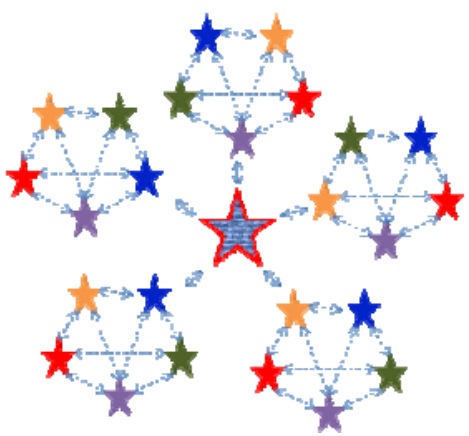

Figure 3. Phase-III: Meta-reflection Teams

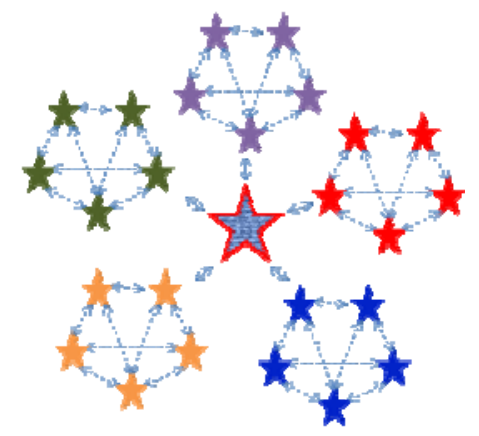

Figure 2. Phase-II: Teamwork

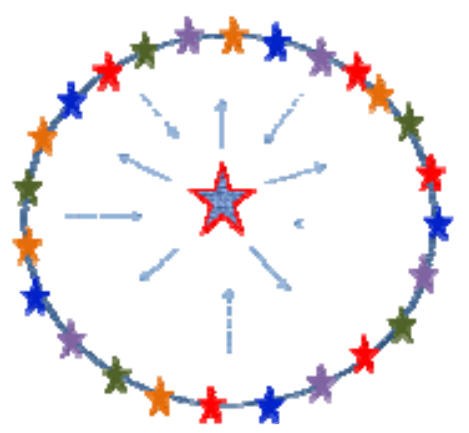

Figure 4. Phase-V: Feedback in Plenary 